Popovych Igor L., Mysula Igor R., Popovych Dariya V., Mysula Yuriy I., Sydliaruk Nataliya I., Yavorska Oksana L., Zukow Walery. Role of trace elements of mineral waters in their effects on neuro-endocrine-immune complex at female rats. Journal of Education, Health and Sport. 2021;11(10):373-384. eISSN 2391-8306. DOI http://dx.doi.org/10.12775/JEHS.2021.11.10.035 https://apcz.umk.pl/czasopisma/index.php/JEHS/article/view/JEHS.2021.11.10.035 https://zenodo.org/record/5856442

\footnotetext{
The journal has had 5 points in Ministry of Science and Higher Education parametric evaluation. § 8. 2) and § 12. 1. 2) 22.02.2019. (c) The Authors 2021 ;

This article is published with open access at Licensee Open Journal Systems of Nicolaus Copernicus University in Torun, PolandOpen Access. This article is distributed under the terms of the Creative Commons Attribution Noncommercial License which permits any noncommercial use, distribution, and reproduction in any medium,provided the original author (s) and source are credited. This is an open access article licensed under the terms of the Creative Commons Attribution Non commercial license Share

alike.(http://creativecommons.org/licenses/by-nc-sa/4.0/) which permits unrestricted, non commercial use, distribution and reproduction in any medium, provided the work is properly cited.The authors declare that there is no conflict of interests regarding the publication of this paper.

Received: 10.10.2021. Revised: 20.10.2021. Accepted: 30.10.2021.
}

\title{
ROLE OF TRACE ELEMENTS OF MINERAL WATERS IN THEIR EFFECTS ON NEURO-ENDOCRINE-IMMUNE COMPLEX AT FEMALE RATS
}

\author{
Igor L. Popovych ${ }^{1}$, Igor R. Mysula ${ }^{2}$, Dariya V. Popovych ${ }^{2}$, Yuriy I. Mysula ${ }^{2}$, \\ Nataliya I. Sydliaruk ${ }^{2}$, Oksana L. Yavorska ${ }^{2}$, Walery Zukow ${ }^{3 *}$ \\ 'OO Bohomolets' Institute of Physiology, Kyïv, Ukraine \\ ${ }^{2}$ IY Horbachevs'kyi National Medical University, Ternopil', Ukraine \\ ${ }^{3}$ Nicolaus Copernicus University, Torun, Poland \\ *w.zukow@wp.pl
}

\begin{abstract}
Background. Drinking mineral water is one of the ethnopharmacologic factors. Previously, we identified the role of organic carbon and nitrogen of mineral waters in their effects on certain metabolic and neuro-endocrine-immune parameters. The purpose of this study is to clarify the role of trace elements of same mineral waters in their effects on neuro-endocrine-immune complex parameters. Material and methods. Experiment was performed on 48 healthy female Wistar rats 240-290 g divided into 5 groups. Animals of the first group for 6 days administered a single tap water through the tube at a dose of 1,5 $\mathrm{mL} / 100 \mathrm{~g}$ of body mass. In the second group we administered the water Naftussya from the Truskavets' layer (Galychyna, Ukraine), in the third group the water Sophiya of the Truskavets' field. The rats of the fourth group received the native water from the Hertsa (Bucovyna, Ukraine) field, and the last group received its artificial salt analogue. The day after the completion of the drinking course in all rats HRV, endocrine and immunne parameters were registered. Results. The trace elements (fluoride, bromide, iodide, meta-silicic and orthoboric acids) of the chemical composition of loading fluids determine their effect on the neuro-endocrine parameters by $59 \%$, on the immune parameters by $84 \%$. Conclusion. The trace elements (fluoride, bromide, iodide, meta-silicic and orthoboric acids) of mineral waters play an essential role in their effects on the neuro-endocrine-immune parameters of female rats.
\end{abstract}

Key words: Mineral waters, trace elements, female rats, neuro-endocrine-immune parameters, relationships. 


\section{Introduction}

Drinking mineral water is one of the ethnopharmacological factors. Back in 1975, trace elements of mineral waters have been considered as biologically active factors, but systematic studies of their impact on the body have not yet been conducted [1]. The monograph published in 2009 [2] only confirmed the superficiality of our knowledge.

Previously, we have shown that drinking water with different contents of electrolytes, trace elements and organic substances has both general [3] and different effects on the parameters of metabolism [4] and the neuroendocrine-immune complex [5] in female rats, which they have been drinking for 6 days.

In the next study, we identified the role of organic carbon and nitrogen of mineral waters in their effects on certain metabolic [6] and neuroendocrine [7] parameters.

\section{Objective}

The purpose of this study is to clarify the role of trace elements of mineral waters in their effects on certain neuro-endocrine-immune parameters.

\section{Methods}

Experiment was performed on 48 healthy female Wistar rats 240-290 g divided into 5 groups. Rats of the first (control) group for 6 days administered a single tap water through the tube at a dose of 1,5 $\mathrm{mL} / 100 \mathrm{~g}$ of body mass. In the second group was given daily drinking of animals with water Naftussya from the Truskavets' (Galychyna, Ukraine) layer, in the third group the rats were louded with the water Sophiya of the Truskavets' field. The rats of the fourth group received the native water from the Hertsa (Bucovyna, Ukraine) field, and the last - its artificial salt analogue. The chemical composition of the applied waters (according to Truskavetsian Hydrogeological Regime-Operational Station data) is given in Table 1.

The day after the completion of the drinking course in rats, at first, a sample of peripheral blood (by incision of the tip of the tail) was taken for analysis of
Leukocytogram (LCG), ie the relative content of lymphocytes (L), monocytes (M), eosinophils (Eo), basophils (Bas), rod-shaped (RN) and segmental (SN) neutrophils. Based on these data, the Entropy of the Leukocytogram (hLCG) was calculated according to the formula derived by IL Popovych [8] on the basis of the classical CE Shannon formula:

hLCG

$[\mathrm{L} \cdot \log 2 \mathrm{~L}+\mathrm{M} \cdot \log 2 \mathrm{M}+\mathrm{Eo} \cdot \log 2 \mathrm{Eo}+\mathrm{Bas} \cdot \log 2 \mathrm{Bas}+\mathrm{RN} \bullet \operatorname{lo}$ $\mathrm{g} 2 \mathrm{RN}+\mathrm{SN} \bullet \log 2 \mathrm{SN}] / \log 26$.

Next assessed the state of autonomous regulation. For this purpose, under an easy ether anesthesia, for $15-20 \mathrm{sec}$ ECG was recorded in the lead II, inserting needle electrodes under the skin of the legs, followed by the calculation of the parameters of the HRV: mode (Mo), amplitude of the mode (AMo) and variational swing (MxDMn) as markers of the humoral channel of regulation, sympathetic and vagal tones respectively [9].

Animals were then placed in individual chambers with perforated bottom for collecting daily urine. The experiment was completed by decapitation of rats in order to collect as much blood as possible.

The plasma levels of the hormones of adaptation: corticosterone, triiodothyronine and testosterone (by the ELISA [10]) were determined.

Electrolytes: calcium (by reaction with arsenase III), phosphates (phosphate-molybdate method), sodium and potassium (flamming photometry) were determined in plasma and daily urine. The analyzes were carried out according to the instructions described in the manual [11].

The analyzers "Tecan" (Oesterreich), "Pointe-180" ("Scientific", USA) and "Reflotron" (Boehringer Mannheim, BRD) were used with appropriate sets and a flamming spectrophotometer "СФ-47".

According to the parameters of electrolyte exchange, hormonal activity was evaluated: parathyroid, calcitonin and mineralocorticoid, based on their classical effects.

In the adrenal glands after weighing, the thickness of glomerular, fascicular, reticular and medullar zones was measured under a microscope [12-14].

The parameters of immunity were determined as described in the manual [15]: the relative content of the 
population of T-lymphocytes in a test of spontaneous rosette formation with erythrocytes of sheep, their theophylline-resistant and theophylline-susceptible subpopulations (by the test of sensitivity of rosette formation to theophylline); the population of Blymphocytes (by the test of complementary rosette formation with erythrocytes of sheep). Natural killers were identified as large granules contain lymphocytes. The content of 0-lymphocytes was calculated by the balance method.

About the condition of the phagocytic function of neutrophils (microphages) and monocytes (macrophages) were judged by the phagocytosis index, the microbial count and the killing index for Staphylococcus aureus (ATCC N25423 F49) $[12,16]$.

Immune organs weighed and made smears-imprints for counting Thymocytogram and Splenocytogram. The components of the thymocytogram (TCG) are lymphocytes (Lc), lymphoblasts (Lb), reticulocytes (R), macrophages (Mac), endotheliocytes (En), epitheliocytes (Ep) and Hassal's corpuscles (Has). The Splenocytogram (SCG) includes lymphocytes (Lc), lymphoblasts (Lb), plasma cells $(\mathrm{P})$, reticulocytes $(\mathrm{R})$, macrophages $(\mathrm{Ma})$, fibroblasts $(\mathrm{F})$, microphages $(\mathrm{Mi})$ and eosinophils (E) [14,17].

For them CE Shannon's entropy was calculated too by using formulas $[17,18]$ :

hTCG

$[\mathrm{Lc} \bullet \log 2 \mathrm{Lc}+\mathrm{Lb} \bullet \log 2 \mathrm{Lb}+\mathrm{R} \bullet \log 2 \mathrm{R}+\mathrm{Mac} \bullet \log 2 \mathrm{Mac}+\mathrm{En} \bullet 1$ og2En+Ep•log2Ep+Has $\bullet \log 2 \mathrm{Has}] / \log 27$

hSCG $=$

$[\mathrm{Lc} \bullet \log 2 \mathrm{Lc}+\mathrm{Lb} \bullet \log 2 \mathrm{Lb}+\mathrm{P} \bullet \log 2 \mathrm{P}+\mathrm{R} \bullet \log 2 \mathrm{R}+\mathrm{Ma} \bullet \log 2 \mathrm{M}$ $\mathrm{a}+\mathrm{F} \bullet \log 2 \mathrm{~F}+\mathrm{Mi} \bullet \log 2 \mathrm{Mi}+\mathrm{E} \bullet \log 2 \mathrm{E}] / \log 28$

Digital material is statistically processed on a computer using the software package "Statistica 64".

\section{Results}

The calculations by the formula:

$|r| \geq\{\exp [2 t /(n-1,5) 0,5]-1\} /\{\exp [2 t /(n-1,5) 0,5]$

$+1\}$,

showed that for a sample of 48 animals, the critical value of the modulus of the correlation coefficient $|r|$ for $p<0,05(t>2,0)$ is 0,28 , for $p<0,01$ $(\mathrm{t}>2,7)$ is 0,38 .
According to the correlation matrix (Table 2), the trace elements found in mineral waters are only moderately and weakly related to the neuroendocrine parameters of the animals consuming them.

Fluoride has the most significant hormonemodulating effect, reducing parathyroid activity and plasma corticosterone and triiodothyronine levels, while increasing mineralocorticoid activity and plasma testosterone levels.

The hormone-modulating effect of meta-silicic acid is of the same significant force, but has upregulating character and concerns other neuroendocrine constellations. In particular, it causes an increase in adrenal mass and increase their mineralocorticoid and glucocorticoid activity, as well as sympathetic tone, reciprocally reducing the oscillatory tone.

The degree of hormone-modulating effect of bromide passes to the category of moderate, but statistically significant. It is manifested in a decrease in plasma levels of triiodothyronine and corticosterone and increased mineralocorticoid activity.

While the association with animal endocrine parameters of orthoboric acid and iodide is weak and statistically insignificant.

The combined modulating effect of trace elements of mineral waters on neuroendocrine parameters is much stronger than the partial effects: the degree of determination reaches 59\% (Table 3 and Fig. 1). The maximum factor load on the trace element canonical root is given by fluoride, less by metasilicic acid and bromide, while the loads by orthoboric acid and iodide are negligible. Neuroendocrine root reflects the downregulation by trace elements of plasma levels of triiodothyronine and, to a lesser extent, testosterone on the one hand, and the upregulation of sympathetic tone, adrenal mass and their mineralocorticoid and, to a lesser extent, glucocorticoid activity.

The correlation matrix for trace elements of mineral waters and immune parameters of animals has the following form (Table 4).

Comparative analysis of regression models showed that bromide has the most significant immunotropic activity. It is manifested in the activating effect on the intensity of phagocytosis of blood neutrophils, the content of leukocytes in general and the share in the leukocytogram of basophils, while the share of lymphocytes in the leukocytogram and thymocytogram decreases, as well as the share in the splenocytogram of fibroblasts, reticulocytes and eosinophils. The degree of immunomodulatory determination is $65,5 \%$. 
Metasilicic acid has a less noticeable immunomodulatory effect (the coefficient of determination is $53 \%$ ). It is manifested in a suppressive effect on the level in the blood of natural killers and total lymphocytes, the activity of phagocytosis of blood monocytes, the content in the spleen of fibroblasts and reticulocytes, and in the thymus macrophages. Instead, the content of endothelial cells and lymphoblasts in the thymus, in the spleen of macrophages, and in the blood of 0-lymphocytes decreases.

The immunomodulatory effect of orthoboric acid and iodide was almost similar in strength. These micronutrients equally contribute to the increase in the content of leukocytes in the blood and the share of polymorphonuclear neutrophils and basophils in the leukocytogram and to the decrease in the content of reticulocytes and fibroblasts in the splenocytogram.

Minimal immunomodulatory activity (coefficient of determination 34\%) was found in fluoride, which downregulate the level of natural killers in the blood and microphages in the spleen and the entropy of the splenocytogram, instead upregulate its content of macrophages as well as blood Blymphocytes and thymic plasmocytes.

According to the canonical correlation analysis, the most active immunotropic trace element is metasilicic acid; bromide, orthoboric acid and iodide are slightly inferior in factor loads, while fluoride lags far behind (Table 5).

Among the parameters of immunity to the upregulation subordinates, primarily responsible for phagocytosis: the microbial count of neutrophils, their share in the leukocytogram and the total content of leukocytes in the blood, which together reflects its bactericidal ability. Other objects of upregulation are endothelial cells and lymphoblasts of the thymus and macrophages and microphages of the spleen.

In contrast, to the downregulation subordinate lymphocytes in general and natural killers and Blymphocytes in particular, as well as fibroblasts, reticulocytes and eosinophils of the spleen and the associated entropy of the splenocytogram. The increase in the proportion of 0-lymphocytes in the immunocytogram of the blood reflects, in essence, the immunosuppressive effect of trace elements. Taken together, these trace elements determine the immune status of animals by $84 \%$ (Fig. 2).

It is known that the nervous, endocrine and immune systems interact closely within the triune neuro-endocrine-immune complex [13,14,18-22]. Therefore, at the final stage, a canonical correlation analysis of neuroendocrine-immune relationships in our rats was performed. Initially, a matrix of noteworthy correlations between neuroendocrine parameters, on the one hand, and immunity indicators, on the other, was created. For further consideration, two pairs of significantly related pairs of canonical radicals were selected (Table 6).

It was found that the neuroendocrine root of the first pair receives the maximum positive factor load from triiodothyronine, less pronounced - from markers of glucocorticoid, mineralocorticoid and androgenic functions of the adrenal cortex, circulating catecholamines, as well as parathyroid activity, while negative - from the adrenaline-secreting medullary zone of the adrenal glands, vagal tone and calcitonin activity. The immune root is represented by the parameters of the blood, thymus, as well as plasma cells and lymphoblasts of the spleen, which are subject to the types of upregulation/downregulation influences. The degree of neuroendocrine immunomodulation is very significant $-96,5 \%$ (Fig. 3 ).

The neuro-endocrine root of the second pair is represented by sympathetic tone, glomerular zone of the adrenal cortex and, conversely, corticosterone. Sympathetic tone carries out upregulation of macrophages of a spleen. Corticosterone has a suppressive effect on T-killers and B-lymphocytes and reduces the entropy of the leukocytogram and thymocytogram. Mineralocorticoids are responsible for increasing the mass of the thymus and reducing the content of fibroblasts in the spleen. The degree of immunomodulation by this neuroendocrine constellation is less pronounced - $87 \%$ (Fig. 4).

These experimental data are in good agreement with the results of our clinical observations on the relationship between the autonomic nervous system and immune parameters [23-26].

\section{Discussion}

As far as we can judge from the available literature, our study is the first fundamental to elucidating the role of trace elements in mineral waters in their effect on the neuro-endocrine-immune complex. In the monograph [2] quoted at the beginning, the data are extremely fragmentary.

In particular, it states that water containing metasilicic acid causes a decrease in the content of leukocytes in rats by reducing the number of neutrophils, acidophils and monocytes. The content of lymphocytes does not change, ie the protective function of peripheral blood is somewhat weakened, 
but the system of recognition of strangers operates normally. The change also occurs in the functional system of the immune response. First of all, the total number of neutrophils (nonspecific phagocytes) is somewhat reduced, but their absorption function and the number of active phagocytes remain at the control level. At the same time, the concentration of circulating immune complexes increases and the content of heterophilic antibodies changes, ie the humoral component of the immune response, which is not only a protective but also a regulatory system, is at a fairly active level. In general, according to the authors, it is possible to assume that under the influence of mineral waters enriched with meta-silicic acid, the protective system becomes more effective because its normal activity is provided by fewer elements.

Course consumption of mineral waters with high content of orthoboric acid, according to authors from Odesa, causes an increase in blood leukocytes by $39 \%$, neutrophils - by $35,3 \%$ and a decrease in monocytes by $40 \%$ while maintaining the content of lymphocytes and acidophiles at the control level. That is, according to the authors, the use of such waters somewhat enhances the non-specific protective forces of the blood system and inhibits subtle specific phagocytosis. The immune response is manifested by an increase in the level of heterogeneous antibodies by $24 \%$, complement by $12,5 \%$ and circulating immune complexes by $30 \%$. In general, the authors claim that the humoral part of the immune system is activated, which is more related to the function of regulation than protection.

\section{Conclusion}

Taken together, these results indicate that the trace elements (fluoride, bromide, iodide, metasilicic and orthoboric acids) of mineral waters play an essential role in their effects on the autonomic nervous, endocrine and immune systems, which are known to interact closely within the triune neuro-endocrineimmune complex.

\section{Conformity to ethical standards}

Experiments on animals have been carried out in accordance with the provisions of the Helsinki Declaration of 1975, revised and supplemented in 2002 by the Directives of the National Committees for Ethics in Scientific Research.
The carrying out of experiments was approved by the Ethics Committee of the Horbachevs'kyi Ternopil' National Medical University. The modern rules for the maintenance and use of laboratory animals complying with the principles of the European Convention for the Protection of Vertebrate Animals used for scientific experiments and needs are observed (Strasbourg, 1985).

Conflict of interest. The authors declare that they have no conflict of interest.

\section{References}

1.Tsarfis, P.G., Danilova, Yu.Ye. (1975). Basic Principles of Treatment for Patients at the Resorts of the USSR. Moskva. Meditsina; 312. [In Russian].

2.Babov, K.D., Zolotaryova, T.A., Nasibullin, B.A., Nikipelova, O.M., Pavlova, O.S., Alyeksyeyenko, N.O., Oleshko, A.Y. (2009). Features of biological action of mineral waters of different mineralization. Kyiv. KIM: 60 .

3.Zavidnyuk, Y.V., Mysula, I.R., Klishch, I.M., Zukow, W., Popovych, I.L., Korda, M.M. (2018). General nonspecific metabolic, neuroendocrine and immune reactions to various water-salt loads in female rats. Journal of Education, Health and Sport, 8(3): 513-524.

4.Gozhenko, A.I., Zavidnyuk, Y.V., Sydliaruk, N.I., Mysula, I.R., Klishch, I.M., Zukow, W. Et al. (2018). Features of metabolic reactions to various water-salt loads in female rats. Journal of Education, Health and Sport, 8(4): 496-518.

5.Gozhenko, O.A., Zavidnyuk, Y.V., Korda, M.M., Mysula, I.R., Klishch, I.M., Zukow, W., Popovych, I.L. (2018). Features of neuro-endocrine and immune reactions to various water-salt loads in female rats. Journal of Education, Health and Sport, 8(9): 11-31.

6.Popovych, I.L., Zavidnyuk, Y.V., Korda, M.M., Mysula, I.R., Klishch, I.M., Zukow, W. (2018). Role of organic carbon and nitrogen of mineral waters in their metabolic effects at female rats. Journal of Education, Health and Sport, 8(12): 793-802.

7.Zukow, W., Gozhenko, O.A., Zavidnyuk, Y.V., Korda, M.M., Mysula, I.R., Klishch, I.M. et al. (2020). Role of organic carbon and nitrogen of mineral waters in their neuro-endocrine effects at female rats. International $J$ of Applied Exercise Physiology, 9(4): 20-25.

8.Popovych, I.L. (2007). Information effects of bioactive water Naftyssya in rats: modulation entropic, prevention desynchronizing and limitation of disharmonizing actions water immersion stress for 
information components of neuro-endocrine-immune system and metabolism, which correlates with gastroprotective effect. Medical Hydrology and Rehabilitation, 5(3): 50-70. [in Ukrainian].

9.Baevskiy, R.M., Ivanov, G.G. (2001). Heart Rate Variability: theoretical aspects and possibilities of clinical application. Ultrazvukovaya i funktsionalnaya diagnostika. 3: 106-127. [in Russian].

10.Instructions for use of a set of reagents for enzymelinked immunosorbent assay of hormones in human blood. (2000). St-Pb. CJSC "Alcor Bio" [in Russian].

11.Goryachkovskiy, A.M. (1998). Clinical Biochemistry. Odesa. Astroprint; 608. [in Russian]. 12.Bilas, V.R., Popovych, I.L. (2009). Role of microflora and organic substances of water Naftussya in its modulating influence on neuroendocrine-immune complex and metabolism. Medical Hydrology and Rehabilitation. 7(1): 68-102. [in Ukrainian].

13.Popovych, I.L. (2011). Stresslimiting Adaptogene Mechanism of Biological and Curative Activity of Water Naftussya. Kyiv. Computerpress; 300. [in Ukrainian].

14.Popovych, I.L., Gozhenko, A.I., Zukow, W., Polovynko, I.S. (2020). Variety of Immune Responses to Chronic Stress and their Neuro-Endocrine Accompaniment. Scholars' Press. Riga; 172.

15.Perederiy, V.G., Zemskov, A.M., Bychkova, N.G., Zemskov, V.M. (1995). Immune status, principles of its evaluation and correction of immune disorders. Kyiv. Zdorovya; 211. [in Russian].

16.Douglas, S.D., Quie, P.G. (1981). Investigation of Phagocytes in Disease. Churchil. 110.

17.Bilas, V.R., Popadynets', O.O., Flyunt, I-S.S., Sydoruk, N.O., Badiuk, N.S., Gushcha, S.G. et al. (2020). Entropies of thymocytogram, splenocytogram, immunocytogram and leukocytogram in rats are regulated by sex and the neuroendocrine parameters while regulates immune parameters. Journal of Education, Health and Sport, 10(7): 266-288.

18.Popadynets', O., Gozhenko, A., Badyuk, N., Popovych, I., Skaliy, A., Hagner-Derengowska, M. et al (2020). Interpersonal differences caused by adaptogen changes in entropies of EEG, HRV, immunocytogram, and leukocytogram. Journal of Physical Education and Sport, 20(Suppl 2), 982-999.

19.Thayer, J.F., Sternberg, E.M. (2010). Neural aspects of immunomodulation: Focus on the vagus nerve. Brain Behav Immun, 24(8): 1223-1228.

20.Chavan, S.S., Pavlov, V.A., Tracey, K.J. (2017). Mechanism and therapeutic relevance of neuroimmune communication. Immunity, 46: 927-942.

21.Chavan, S.S., Tracey, K.J. (2017). Essencial Neuroscience in Immunology. J Immunol, 198: 33893397.

22.Pavlov, V.A., Chavan, S.S., Tracey, K.J. (2018). Molecular and functional neuroscience in immunity. Annu Rev Immunol, 36: 783-812.

23.Kul'chyns'kyi, A.B., Kyjenko, V.M., Zukow, W., Popovych, I.L. (2017). Causal neuro-immune relationships at patients with chronic pyelonephritis and cholecystitis. Correlations between parameters EEG, HRV and white blood cell count. Open Medicine. 12(1): 201-213.

24.Kul'chyns'kyi, A.B., Zukow, W., Korolyshyn, T.A., Popovych, I.L. (2017). Interrelations between changes in parameters of HRV, EEG and humoral immunity at patients with chronic pyelonephritis and cholecystitis. Journal of Education, Health and Sport. 7(9): 439-459.

25.Popovych, I.L., Kul'chyns'kyi, A.B., Gozhenko, A.I., Zukow, W., Kovbasnyuk, M.M., Korolyshyn, T.A. (2018). Interrelations between changes in parameters of HRV, EEG and phagocytosis at patients with chronic pyelonephritis and cholecystitis. Journal of Education, Health and Sport. 8(2): 135-156.

26.Popovych, I.L., Kul'chyns'kyi, A.B., Korolyshyn, T.A., Zukow, W. (2017). Interrelations between changes in parameters of HRV, EEG and cellular immunity at patients with chronic pyelonephritis and cholecystitis. Journal of Education, Health and Sport. 7(10): 11-23. 
Table 1. The chemical composition of the applied mineral waters

\begin{tabular}{|l|c|l|l|c|c|}
\hline & Tap Water & Sofiya & Hertsa & Salt analogue & Naftussya \\
\hline \multicolumn{7}{|c|}{ Electrolytes, mM/L } \\
\hline $\mathrm{Na}^{+}$ & 0,5 & 156 & 196,7 & 196,7 & 0,6 \\
\hline $\mathrm{Cl}^{-}$ & 3,4 & 142 & 205 & 205 & 1,0 \\
\hline $\mathrm{HCO}_{3}{ }^{-}$ & 2,9 & 7,5 & 5,6 & 5,6 & 8,2 \\
\hline $\mathrm{Ca}^{2+}$ & 3,4 & 5,3 & 3,40 & 3,40 & 2,9 \\
\hline $\mathrm{Mg}^{2+}$ & 0,5 & 4,3 & 3,44 & 3,44 & 2,3 \\
\hline $\mathrm{K}^{+}$ & 0,4 & 0,3 & 0,4 & 0,4 & 0,3 \\
\hline $\mathrm{SO}_{4}{ }^{2-}$ & 1,2 & 13,1 & 0,1 & 0,1 & 1,0 \\
\hline \multicolumn{7}{|c|}{ Trace elementes, mg/L } \\
\hline $\mathrm{H}_{2} \mathrm{SiO}_{3}$ & 5 & 4,43 & 9,88 & 0 & 9,5 \\
\hline $\mathrm{H}_{3} \mathrm{BO}{ }_{3}$ & 0,25 & 8,39 & 42,76 & 0 & 0,200 \\
\hline $\mathrm{Br}$ & 8,3 & 6,7 & 21,17 & 0 & 0,034 \\
\hline $\mathrm{J}$ & 0,025 & 1,29 & 6,62 & 0 & 0,004 \\
\hline $\mathrm{F}$ & 0,95 & 0,52 & 0,57 & 0 & 0,160 \\
\hline \multicolumn{7}{|c|}{ Organic substances, mg/L } \\
\hline $\mathrm{C}$ org & 5,0 & 5,5 & 34 & 0 & 13,8 \\
\hline $\mathrm{N}$ org & 0,02 & 0,8 & 0,14 & 0 & 0,33 \\
\hline
\end{tabular}

Table 2. Matrix of correlations between the content of trace elements in fluids and neuroendocrine parameters after weekly water-salt loads

\begin{tabular}{|l|c|c|c|c|c|}
\hline \multicolumn{1}{|c|}{ Neuroendocrine parameters } & $\mathrm{F}^{-}$ & $\mathrm{H}_{2} \mathrm{SiO}_{3}$ & $\mathrm{Br}^{-}$ & $\mathrm{H}_{3} \mathrm{BO}_{3}$ & $\mathrm{~J}^{-}$ \\
\hline Variative Swing HRV as Vagal Tone, msec &,- 06 &,- 18 &, 01 &, 03 &, 03 \\
\hline Mode HRV, msec &,- 18 &,- 12 &,- 11 &,- 06 &,- 06 \\
\hline AMo HRV as Sympathetic Tone, $\%$ &, 17 &, 26 &, 01 &,- 04 &,- 04 \\
\hline$(\mathrm{Nap} / \mathrm{Kp})^{0,5}$ as Mineralocorticoid Activity &, 17 &,- 07 &, 18 &, 15 &, 15 \\
\hline$(\mathrm{Nap} \cdot \mathrm{Ku} / \mathrm{Kp} \cdot \mathrm{Nau})^{0,25}$ as Mineralocorticoid Activity &, 19 & $\mathbf{2 8}$ &,- 08 &,- 16 &,- 16 \\
\hline$(\mathrm{Cap} / \mathrm{Pp})^{0,5}$ as Parathyroid Activity & $\mathbf{- , 3 0}$ &,- 21 &,- 02 &, 09 &, 09 \\
\hline$(\mathrm{Cap} \cdot \mathrm{Pu} / \mathrm{Pp} \cdot \mathrm{Cau})^{0,25}$ as Parathyroid Activity &,- 23 &,- 29 &, 01 &, 09 &, 09 \\
\hline$(\mathrm{Pp} \cdot \mathrm{Cap})^{-0,5}$ as Calcitonin Activity &, 16 &, 02 &, 21 &, 17 &, 17 \\
\hline$(\mathrm{Cau} \cdot \mathrm{Pu} / \mathrm{Pp} \cdot \mathrm{Cap})^{0,25}$ as Calcitonin Activity &,- 13 &,- 03 &, 02 &, 07 &, 07 \\
\hline Triiodothyronine, $\mathrm{nM} / \mathrm{L}$ &,- 27 &, 01 &,- 31 &,- 23 &,- 23 \\
\hline Testosterone, $\mathrm{nM} / \mathrm{L}$ &, 19 &, 04 &,- 09 &,- 20 &,- 20 \\
\hline $\mathrm{Corticosterone,} \mathrm{nM} / \mathrm{L}$ &,- 29 &, 25 &,- 24 &,- 14 &,- 14 \\
\hline Glomerular Zone of Adrenal Cortex, $\mu \mathrm{M}$ &,- 01 &,- 03 &, 12 &, 14 &, 13 \\
\hline Fascicular Zone of Adrenal Cortex, $\mu \mathrm{M}$ &,- 13 &,- 01 &,- 22 &,- 19 &,- 19 \\
\hline Reticular Zone of Adrenal Cortex, $\mu \mathrm{M}$ &,- 14 &, 01 &,- 11 &,- 08 &,- 08 \\
\hline Adrenals Mass Index, \% &, 07 & $\mathbf{3 6}$ &,- 08 &,- 11 &,- 11 \\
\hline
\end{tabular}

Table 3. Factor structure of the canonical roots, which represent the content in liquids of trace elements and neuro-endocrine parameters

\begin{tabular}{|l|l|}
\hline \multicolumn{1}{|c|}{ Trace elements } & $\mathrm{R}$ \\
\hline $\mathrm{F}^{-}$ & $\mathbf{- 0 , 5 1 9}$ \\
\hline $\mathrm{H}_{2} \mathrm{SiO}_{3}$ & $\mathbf{- 0 , 4 3 0}$ \\
\hline $\mathrm{Br}^{-}$ & $\mathbf{- 0 , 2 9 1}$ \\
\hline $\mathrm{H}_{3} \mathrm{BO}_{3}$ & $-0,120$ \\
\hline $\mathrm{J}^{-}$Neuroendocrine parameters & $-0,118$ \\
\hline \multicolumn{2}{|c|}{$\mathrm{R}$} \\
\hline Triiodothyronine, nM/L & $\mathbf{0 , 6 9 7}$ \\
\hline Testosterone, nM/L & 0,031 \\
\hline
\end{tabular}




\begin{tabular}{|l|c|}
\hline AMo HRV as Sympathetic Tone, $\%$ & $\mathbf{- 0 , 3 5 4}$ \\
\hline Adrenals Mass Index, $\%$ & $\mathbf{- 0 , 3 3 3}$ \\
\hline$(\text { Nap } \bullet \mathrm{Ku} / \mathrm{Kp} \cdot \mathrm{Nau})^{0,25}$ as Mineralocorticoid Activity & $\mathbf{- 0 , 2 8 1}$ \\
\hline Corticosterone, $\mathrm{nM} / \mathrm{L}$ & $-0,083$ \\
\hline
\end{tabular}

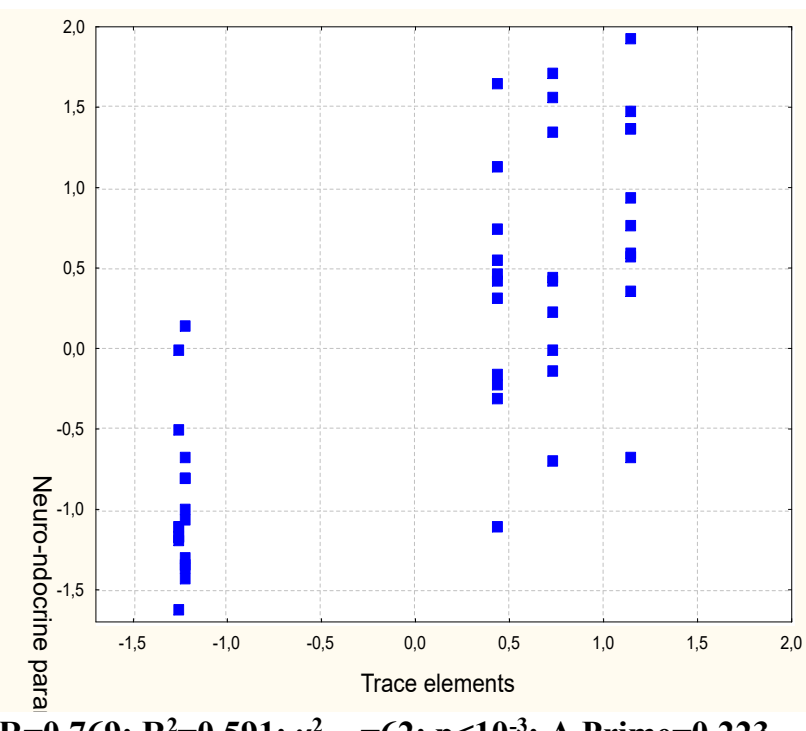

$\mathbf{R}=0,769 ; \mathbf{R}^{2}=0,591 ; \chi^{2}(30)=62 ; p<10^{-3} ; \Lambda$ Prime $=0,223$

Fig. 1. Scatterplot of canonical correlation between the roots, which represent the content in liquids of trace elements ( $\mathrm{X}$-axis) and neuro-endocrine parameters (Y-axis)

Table 4. Matrix of correlations between the content of trace elements in the fluids and the immune parameters of the thymus, spleen and blood after weekly water-salt loads

\begin{tabular}{|c|c|c|c|c|c|}
\hline Immune parameters & $\begin{array}{l}\mathrm{H}_{2} \mathrm{SiO} \\
3\end{array}$ & $\begin{array}{l}\mathrm{H}_{3} \mathrm{BO} \\
3\end{array}$ & $\mathrm{Br}^{-}$ & $\mathbf{J}^{-}$ & $F^{-}$ \\
\hline Thymus Mass Index, mg/100 g BM & 0,12 & 0,01 & 0,03 & 0,01 & 0,04 \\
\hline Lymphocytes of Thymus, \% & $-0,10$ & $-0,13$ & $-0,16$ & $-0,13$ & $-0,14$ \\
\hline Lymphoblastes of Thymus, \% & 0,28 & 0,04 & 0,05 & 0,04 & 0,09 \\
\hline Reticulocytes of Thymus, \% & $-0,00$ & 0,04 & 0,07 & 0,04 & 0,10 \\
\hline Epitheliocytes of Thymus, \% & $-0,06$ & 0,05 & 0,03 & 0,05 & $-0,03$ \\
\hline Endotheliocytes of Thymus, \% & 0,30 & 0,11 & 0,08 & 0,11 & $-0,01$ \\
\hline Plasmocytes of Thymus, \% & 0,14 & 0,10 & 0,16 & 0,10 & 0,22 \\
\hline Macrophages of Thymus, $\%$ & $-0,25$ & $-0,02$ & 0,02 & $-0,02$ & 0,04 \\
\hline Hassal corpuscles of Thymus, $\%$ & $-0,03$ & $-0,05$ & $-0,07$ & $-0,05$ & $-0,04$ \\
\hline Entropy of Thymocytogram & & 0 & 0,18 & 0,14 & 0,17 \\
\hline Spleen Mass Index, mg/100 g BM & 0,15 & 0,00 & $-0,06$ & 0,00 & $-0,13$ \\
\hline Lymphoblastes of Spleen, \% & $-0,03$ & 0,13 & 0,10 & 0,13 & $-0,04$ \\
\hline Lymphocytes of Spleen, \% & $-0,08$ & 0,26 & 0,34 & 0,26 & 0,26 \\
\hline Plasmocytes of Spleen, \% & 0,07 & 0,01 & 0,02 & 0,00 & 0,03 \\
\hline Reticulocytes of Spleen, \% & $-0,16$ & $-0,28$ & $-0,27$ & $-0,28$ & $-0,06$ \\
\hline Fibroblastes of Spleen, \% & $-0,26$ & $-0,27$ & $-0,28$ & $-0,27$ & $-0,12$ \\
\hline Macrophages of Spleen, \% & 0,25 & 0,03 & 0,08 & 0,03 & 0,16 \\
\hline Microphages of Spleen, $\%$ & 0,20 & 0,07 & $-0,05$ & 0,07 & $-0,24$ \\
\hline Eosinophiles of Spleen, \% & $-0,03$ & $-0,12$ & $-0,16$ & $-0,12$ & $-0,14$ \\
\hline Entropy of Splenocytogram & 0,10 & $-0,20$ & $-0,29$ & $-0,20$ & $-0,27$ \\
\hline
\end{tabular}




\begin{tabular}{|c|c|c|c|c|c|}
\hline Monocytes of Blood, \% & $-0,30$ & $-0,26$ & $-0,34$ & $-0,26$ & $-0,27$ \\
\hline Leukocytes of Blood, $10^{9} / \mathrm{L}$ & 0,26 & 0,18 & 0,25 & 0,18 & 0,27 \\
\hline Lymphocytes of Blood, \% & $-0,22$ & $-0,34$ & $-0,31$ & $-0,34$ & $-0,06$ \\
\hline Stub Neutrophils of Blood, \% & 0,09 & 0,08 & 0,11 & 0,08 & 0,14 \\
\hline Segmented Neutrophiles of Blood, \% & 0,34 & 0,43 & 0,40 & 0,43 & 0,11 \\
\hline Eosinophiles of Blood, \% & $-0,03$ & 0,07 & 0,10 & 0,07 & 0,08 \\
\hline Basophiles of Blood, \% & 0,06 & 0,22 & 0,22 & 0,22 & 0,13 \\
\hline Entropy of Leukocytogra & 0,03 & 0,10 & 0,04 & 0,10 & $-0,05$ \\
\hline Natural Killer Lymphocytes, \% & $-0,30$ & $-0,22$ & $-0,31$ & $-0,22$ & $-0,30$ \\
\hline T-helper Lymphocytes, \% & $-0,02$ & $-0,04$ & $-0,02$ & $-0,04$ & 0,04 \\
\hline T-cytolytic Lymphocytes, \% & $-0,12$ & $-0,01$ & 0,05 & $-0,01$ & 0,15 \\
\hline B-Lymphocytes, \% & $-0,13$ & $-0,06$ & 0,04 & $-0,06$ & 0,26 \\
\hline 0-Lymphocytes, \% & $\mathbf{0 , 2 0}$ & 0,11 & 0,05 & 0,11 & $-0,11$ \\
\hline Entropy of Immunocytogram & $-0,15$ & $-0,01$ & $-0,04$ & $-0,01$ & $-0,11$ \\
\hline Microbian Count of Neutrophils, B/Ph & 0,36 & 0,28 & 0,34 & 0,28 & 0,25 \\
\hline Phagocytic Index of Monocytes, \% & $-0,29$ & $-0,23$ & $-0,25$ & $-0,23$ & $-0,17$ \\
\hline Microbian Count of Monocytes, B/Ph & $-0,29$ & $-0,22$ & $-0,26$ & $-0,22$ & $-0,17$ \\
\hline Killing Index of Neutrophils, \% & 0,10 & 0,16 & 0,09 & 0,16 & $-0,11$ \\
\hline Phagocytic Index of Neutrophils, \% & 0,16 & 0,19 & 0,24 & 0,19 & 0,18 \\
\hline
\end{tabular}

Table 5. Factor structure of the canonical correlation between the roots, which represent the content of trace elements in the fluids and the immune parameters of the thymus, spleen and blood

\begin{tabular}{|c|c|}
\hline Trace elements & $\mathbf{R}$ \\
\hline $\mathrm{H}_{2} \mathrm{SiO}_{3}$ & $-0,737$ \\
\hline $\mathrm{Br}^{-}$ & $-0,689$ \\
\hline $\mathrm{H}_{3} \mathrm{BO}_{3}$ & $-0,674$ \\
\hline $\mathbf{J}^{-}$ & $-0,672$ \\
\hline $\mathbf{F}^{-}$ & $-0,287$ \\
\hline Immune parameters & $\mathbf{R}$ \\
\hline Microbian Count of Neutrophils, B/Ph & $-0,674$ \\
\hline Segmented Neutrophiles of Blood, \% & $-0,414$ \\
\hline Endotheliocytes of Thymus, \% & $-0,345$ \\
\hline 0-Lymphocytes, \% & $-0,321$ \\
\hline Leukocytes of Blood, $10^{9} / \mathrm{L}$ & $-0,284$ \\
\hline Lymphoblastes of Thymus, \% & $-0,201$ \\
\hline Macrophages of Spleen, \% & $-0,162$ \\
\hline Microphages of Spleen, \% & $-0,083$ \\
\hline Natural Killer Lymphocytes, \% & 0,578 \\
\hline Fibroblastes of Spleen, $\%$ & 0,361 \\
\hline Reticulocytes of Spleen, \% & 0,322 \\
\hline B-Lymphocytes, \% & 0,246 \\
\hline Phagocytic Index of Monocytes, \% & 0,170 \\
\hline Pan Lymphocytes of Blood, \% & 0,161 \\
\hline Eosinophiles of Spleen, \% & 0,154 \\
\hline
\end{tabular}






$R=0,919 ; R^{2}=0,844 ; \chi^{2}{ }_{(100)}=133 ; p=0,016 ; \Lambda$ Prime $=0,020$

Fig. 2. Scatterplot of canonical correlation between the roots, which represent the content in liquids of trace elements ( $\mathrm{X}$-axis) and immune parameters (Y-axis)

Table 6. Factor structure of two pairs of canonical roots, which represent neuroendocrine and immune parameters

\begin{tabular}{|l|l|l|}
\hline \multicolumn{1}{|c|}{ Neuro-endocrine factors } & Root 1 & Root 2 \\
\hline Triiodothyronine & $\mathbf{0 , 9 3 5}$ & 0,181 \\
\hline Fascicular Zone Adrenal Cortex & $\mathbf{0 , 5 9 6}$ & 0,348 \\
\hline Mineralocorticoid activity & $\mathbf{0 , 4 0 8}$ & $-0,357$ \\
\hline Reticular Zone Adrenal Cortex & $\mathbf{0 , 3 3 5}$ & $-0,082$ \\
\hline Parathyroid activity & $\mathbf{0 , 2 9 0}$ & 0,009 \\
\hline Catecholamines (1/Mode) & $\mathbf{0 , 2 8 9}$ & $-0,287$ \\
\hline Testosterone & $\mathbf{0 , 1 7 3}$ & $-0,144$ \\
\hline Medullar Zone Adrenal & $\mathbf{- 0 , 4 3 5}$ & 0,303 \\
\hline Calcitonin activity & $\mathbf{- 0 , 3 1 9}$ & 0,074 \\
\hline Vagal tone (MxDMn) & $\mathbf{- 0 , 2 8 5}$ & 0,011 \\
\hline Glomerular Zone Adrenal Cortex & 0,138 & $-\mathbf{0 , 4 8 8}$ \\
\hline Sympathetic tone (AMo) & 0,344 & $-\mathbf{0 , 4 8 4}$ \\
\hline Corticosterone & $-0,056$ & $\mathbf{0 , 3 7 9}$ \\
\hline \hline \multicolumn{1}{|c|}{ Immunity } & Root 1 & Root 2 \\
\hline NK Lymphocytes Blood & $\mathbf{0 , 9 2 8}$ & 0,134 \\
\hline Monocytes Blood & $\mathbf{0 , 9 0 9}$ & 0,128 \\
\hline Microbial Count Monocytes & $\mathbf{0 , 4 9 6}$ & 0,248 \\
\hline Epitheliocytes Thymus & $\mathbf{0 , 4 3 5}$ & $-0,214$ \\
\hline EntropyThymocytogram & $\mathbf{0 , 2 5 6}$ & $-0,287$ \\
\hline Reticulocytes Thymus & $\mathbf{0 , 2 1 3}$ & 0,078 \\
\hline Phagocytic Index Monocytes & $\mathbf{0 , 1 8 5}$ & 0,201 \\
\hline
\end{tabular}




\begin{tabular}{|l|c|c|}
\hline Microbial Count Neutrophils & $\mathbf{- 0 , 9 0 8}$ & $-0,144$ \\
\hline Phagocytic Index Neutrophils & $\mathbf{- 0 , 6 1 0}$ & $-0,275$ \\
\hline Plasmocytes Spleen & $\mathbf{- 0 , 5 1 0}$ & 0,223 \\
\hline Lymphoblastes Spleen & $\mathbf{- 0 , 3 3 4}$ & 0,188 \\
\hline Lymphocytes Thymus & $\mathbf{- 0 , 3 1 0}$ & 0,261 \\
\hline Pan-Lymphocytes Blood & $-\mathbf{0 , 2 5 7}$ & $-0,043$ \\
\hline T-helper Lymphocytes Blood & $\mathbf{- 0 , 1 2 9}$ & $-0,079$ \\
\hline Macrophages Spleen & 0,218 & $\mathbf{- 0 , 5 6 8}$ \\
\hline Thymus Mass Index & $\mathbf{0 , 2 7 7}$ & $\mathbf{- 0 , 4 2 5}$ \\
\hline Entropy Immunocytogram & $-0,028$ & $\mathbf{- 0 , 4 2 3}$ \\
\hline T-cytolytic Lymphocytes Blood & 0,097 & $\mathbf{- 0 , 3 4 7}$ \\
\hline Entropy Leukocytogram & 0,181 & $\mathbf{- 0 , 3 4 4}$ \\
\hline B-Lymphocytes Blood & $-0,126$ & $\mathbf{- 0 , 2 3 2}$ \\
\hline Fibroblastes Spleen & 0,094 & $\mathbf{0 , 1 5 5}$ \\
\hline
\end{tabular}

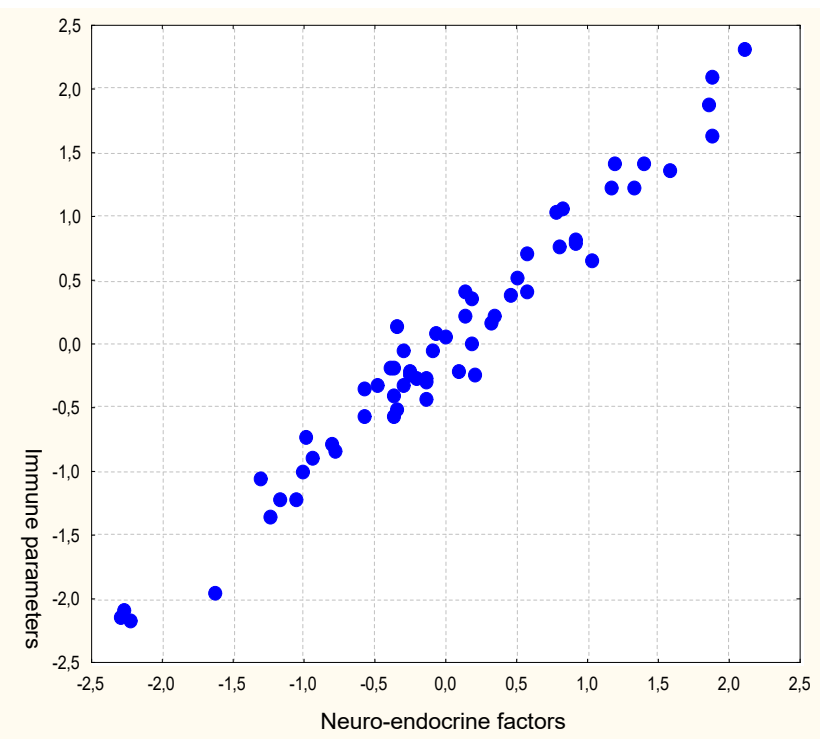

$\mathrm{R}=0,982 ; \mathrm{R}^{2}=0,965 ; \chi^{2}(345)=533 ; \mathrm{p}<10^{-6} ; \Lambda$ Prime $=10^{-6}$

Fig. 3. Scatterplot of canonical correlation between first pair of the roots, which represent the neuroendocrine (X-axis) and immune (Y-axis) parameters 


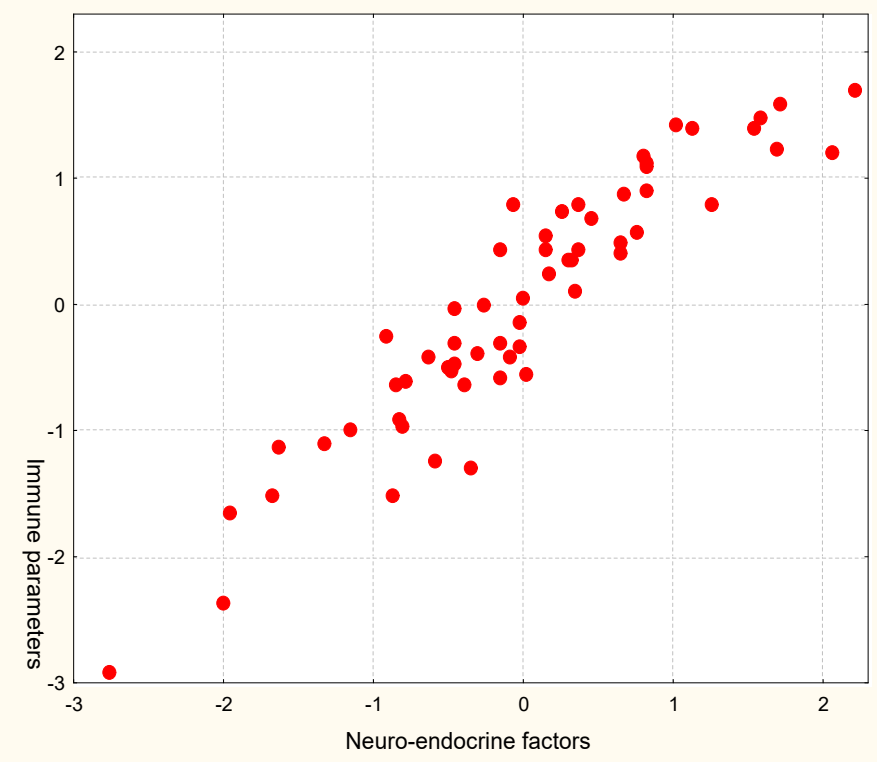

$\mathrm{R}=0,933 ; \mathrm{R}^{2}=0,871 ; \chi^{2}\left({ }_{(308)}=400 ; \mathrm{p}<10^{-3} ; \Lambda\right.$ Prime $=0,00004$

Fig. 4. Scatterplot of canonical correlation between second pair the roots, which represent the neuroendocrine (X-axis) and immune (Y-axis) parameters 